\title{
CD30-positive primary cutaneous lymphoproliferative disorders: molecular alterations and targeted therapies
}

Haematologica 2019

Volume 104(2):226-235

\section{Correspondence: \\ lucia14_prie@msn.com}

Received: September 19, 2018

Accepted: December 7, 2018.

Pre-published: January 10, 2019.

doi:10.3324/haematol.2018.197152

Check the online version for the most updated information on this article, online supplements, and information on authorship \& disclosures: www.haematologica.org/content/104/2/226

(C)2019 Ferrata Storti Foundation

Material published in Haematologica is covered by copyright. All rights are reserved to the Ferrata Storti Foundation. Use of published material is allowed under the following terms and conditions:

https://creativecommons.org/licenses/by-nc/4.0/legalcode. Copies of published material are allowed for personal or internal use. Sharing published material for non-commercial purposes is subject to the following conditions:

https://creativecommons.org/licenses/by-nc/4.0/legalcode, sect. 3. Reproducing and sharing published material for commercial purposes is not allowed without permission in writing from the publisher.

\section{Lucia Prieto-Torres, ${ }^{1}$ Socorro M. Rodriguez-Pinilla, ${ }^{2,3}$ Arantza Onaindia, ${ }^{4}$ Mariano Ara, ${ }^{5}$ Luis Requena ${ }^{1}$ and Miguel Á. Piris ${ }^{2,3}$}

Departments of ${ }^{1}$ Dermatology, ${ }^{2}$ Pathology, Hospital Universitario Fundación Jiménez Díaz, Madrid; ${ }^{3}$ Hospital Universitario Fundación Jiménez Díaz, Madrid, CIBERONC, Madrid, ${ }^{4}$ Pathology, Hospital Universitario Marques de Valdecilla, Santander and ${ }^{5}$ Dermatology Hospital Clínico Universitario Lozano Blesa, Zaragoza, Spain

\section{ABSTRACT}

$\mathrm{P}$ rimary cutaneous CD30-positive T-cell lymphoproliferative disorders are the second most common subgroup of cutaneous T-cell lymphomas. They include two clinically different entities with some overlapping features and borderline cases: lymphomatoid papulosis and primary cutaneous anaplastic large cell lymphoma. Molecular studies of primary cutaneous anaplastic large cell lymphoma reveal an increasing level of heterogeneity that is associated with histological and immunophenotypic features of the cases and their response to specific therapies. Here, we review the most significant genetic, epigenetic and molecular alterations described to date in primary cutaneous CD30-positive T-cell lymphoproliferative disorders, and their potential as therapeutic targets.

\section{Introduction}

$\mathrm{CD}^{+} 0^{+}$primary cutaneous T-cell lymphoproliferative disorders are the second most common subgroup of cutaneous T-cell lymphomas after mycosis fungoides (MF), accounting for approximately $30 \%$ of cases. ${ }^{1}$ These cutaneous lymphomas have customarily been classified on the basis of their clinical presentation into lymphomatoid papulosis (LyP), primary cutaneous anaplastic large cell lymphoma (pcALCL) and borderline cases. In recent years, genomic analysis has become important for the diagnosis and clinical management of patients affected by systemic and cutaneous hematologic malignancies. ${ }^{2}$ Systemic anaplastic large cell lymphoma (ALCL) is defined by mutually exclusive rearrangements of $A L K$, DUSP22/IRF4 and TP63, which have prognostic and survival implications and must be taken into account in the management of patients. ${ }^{2}$ pcALCL have histopathological and immunophenotypic similarities with systemic ALCL, but have a more indolent behavior. Chromosomal translocations described in systemic ALCL can also be seen in pcALCL, although they have different clinical implications. Thus, there are some ALK ${ }^{+}$pcALCL, and some cases of LyP and pcALCL share a DUSP22-IRF4 locus translocation. Bearing all this in mind, we have reviewed the molecular alterations in $\mathrm{CD} 30^{+}$primary cutaneous T-cell lymphoproliferative disorders, describing the various molecular alterations and considering their clinical and therapeutic implications.

\section{Lymphomatoid papulosis}

LyP is an enigmatic disease that follows the course of a chronic skin condition and has the histology of a lymphoma. It typically has a recurrent, self-healing course, with an excellent prognosis. ${ }^{3}$ Clinical features of all types of LyP are similar and consist of papular, papulonecrotic and/or nodular skin lesions at different stages of evolution. The number of lesions is, however, highly variable, ranging from only a few lesions to hundreds. Likewise, there is great variability in the duration of lesions, which may be present for a few weeks or persist for decades. Lyp 
is seen more frequently in adult patients, but children can also be affected. ${ }^{4}$

Customarily, on the basis of its extremely variable histopathology, LyP has been divided into five types with similar prognosis, although distinguishing them is important for the differential diagnosis from more aggressive types of lymphoma..$^{5}$ Although more descriptive terms have been proposed, in 2017 the World Health Organization (WHO) categorized LyP using consecutive alphabetical letters. ${ }^{6}$ Type $A$ is the most frequent form of LyP, accounting for $80 \%$ of cases. Tumor cells are typically $\mathrm{CD}^{+}$and $\mathrm{CD} 30^{+}$and appear scattered or in small clusters, accompanied by numerous inflammatory cells, including neutrophils, eosinophils and small lymphocytes. The main differential diagnoses include reactive lesions, such as insect bites, and pityriasis lichenoides et varioliformis acuta (PLEVA). ${ }^{7}$ Type B is uncommon, accounting for $5 \%$ of cases, and has the same $\mathrm{CD}^{+}, \mathrm{CD}^{-}$immunophenotype. ${ }^{7}$ It has a histology similar to that of plaque-stage $\mathrm{MF}$ with an epidermotropic infiltrate of small, atypical CD30+ cells, which is its main differential diagnosis; less frequently it must be distinguished from cutaneous epidermotropic gamma/delta lymphoma. ${ }^{5}$ Type $C$ makes up around $10 \%$ of LyP cases and has a histology very similar to that of pcALCL, with a nodular cohesive infiltrate of large $\mathrm{CD}^{+} 0^{+}, \mathrm{CD}^{+}, \mathrm{CD}^{-}$pleomorphic and anaplastic tumor cells featuring mitotic figures and abundant cytoplasm. ${ }^{7}$ Apart from pcALCL, other entities, such as transformed $\mathrm{MF}$, peripheral T-cell lymphoma not otherwise specified, and adult T-cell lymphoma/leukemia, may have a similar histology. ${ }^{5}$ Types $\mathrm{D}$ and $\mathrm{E}$ have only been described relatively recently, and are usually characterized by a cytotoxic phenotype, with $\mathrm{CD}^{+}$and $\mathrm{CD}^{+} 0^{+}$lymphocytes. Biopsies from patients with type D LyP show prominent epidermotropism of atypical small-to-medium-sized pleomorphic cells. There may be deep dermal and perivascular infiltrates. This variant accounts for about $5 \%$ of cases and needs to be differentiated from pagetoid reticulosis, a peculiar $\mathrm{CD}^{+}$form of $\mathrm{MF}$, from more aggressive lymphomas such as primary cutaneous aggressive epidermotropic $\mathrm{CD}^{+}$cytotoxic T-cell lymphoma, and from cutaneous gamma/delta lymphoma. ${ }^{8}$ Accounting for fewer than $5 \%$ of cases, type E LyP shows more extensive necrosis and ulceration due to angiocentric and angiodestructive infiltrates of mostly medium-sized, pleomorphic $\mathrm{CD}^{+}$and $\mathrm{CD}^{+} 0^{+}$lymphocytes with hemorrhage, vascular occlusion and thrombi, admixed with some eosinophils. ${ }^{9}$ Although clinically indolent, the histology can be confused with that of extranodal NK/T-cell lymphoma, nasal type, cutaneous gamma/delta lymphoma or ALCL (primary cutaneous or systemic form) with angiocentric and angiodestructive growth. It is important to highlight that histological differential diagnoses of LyP (such as aggressive epidermotropic CD8 ${ }^{+}$cytotoxic T-cell lymphoma or MF) must be excluded by clinicopathological correlation based on characteristic clinical grounds with the typical "waxing and waning" presentation of LyP.

Recently, the detection of rearrangements of the DUSP22-IRF4 locus on chromosome 6p25.3 has enabled the identification of a new molecular-based type of LyP with a characteristic histological pattern. ${ }^{10}$

\section{Lymphomatoid papulosis with 6p25.3 rearrangements}

This molecular alteration at the DUSP22-IRF4 locus is less frequent in LyP than in pcALCL and accounts for fewer than $5 \%$ of cases of LyP. Typically, patients are older than those with other forms of LyP, and their lesions are characterized by a biphasic histological pattern showing, on the one hand, extensive epidermotropism with $\mathrm{CD}_{30} 0^{+}$ small-to-medium-sized T-lymphocytes that simulate pagetoid reticulosis lesions and, on the other, a dermal neoplastic infiltrate composed of large T cells with strong CD30 positivity. ${ }^{11}$

\section{T-cell receptor clonality}

Detection of T-cell receptor clonality differs significantly between LyP types. ${ }^{12}$ This difference might be related to the number of tumor cells present in the infiltrate, which is lower in type A than in type $\mathrm{C}$, hindering the detection technique in paraffin-embedded tissues. LyP presents atypical evolution for a peripheral T-cell lymphoma, exhibiting self-healing lesions and multiple outbreaks. Tcell receptor clonality studies have been performed in various LyP lesions to investigate the potential role of foreign antigens and the relationship between LyP and other cutaneous T-cell lymphomas in cases with overlapping histological findings. Chott et al. showed that multiple skin lesions and associated T-cell lymphomas (MF and ALCL) were clonally related in most LyP patients, which suggests that a non-random genetic event initiates the disease. ${ }^{13}$ Shared clonality has been confirmed for LyP and MF lesions occurring in the same patients by de la Garza Bravos et al. ${ }^{14}$

T-cell receptor- $\gamma$ expression is considered a feature of primary cutaneous gamma-delta T-cell lymphoma, and is rare in other types of primary cutaneous lymphoma. However, there are cases of type D LyP with a cytotoxic phenotype and T-cell receptor- $\gamma$ expression that, unlike in primary cutaneous gamma-delta T-cell lymphoma, is not associated with worse prognosis. ${ }^{15}$

\section{Other findings in lymphomatoid papulosis}

SATB1 (special AT-rich sequence-binding protein 1) is an important thymocyte nuclear protein, a chromatin organizer that is crucial to the development of T-lymphocytes. ${ }^{16,17}$ SATB1 plays a role in inducing resistance to the death of Sézary cells and has been implicated in the pathogenesis of the leukemic form of cutaneous T-cell lymphoma-Sézary syndrome. ${ }^{18}$ Sun et al. investigated its expression in a large cohort of patients with CD30 $0^{+}$lymphoproliferative disorders, and studied the potential for its use in classifying $\mathrm{CD} 0^{+}$lymphoproliferative disorders with differential clinicopathological behaviors and prognoses. ${ }^{19}$ They identified SATB1 expression in anaplastic T cells in $91.7 \%$ of LyP cases and in $38.1 \%$ of pcALCL cases. SATB1 cases showed T-helper 17 polarization with expression of T-helper 17 cytokines and repressed $T$ helper 1-related genes. ${ }^{19}$ They also described a better response to methotrexate and interferon treatment in cases with high levels of SATB1 expression. Furthermore, these cases showed more prominent epidermal hyperplasia and granulocytic infiltration. ${ }^{19}$ Sun et al. postulated that the variability of SATB1 expression in CD30+ lymphoproliferative disorders could be related to the extent of DNA methylation. ${ }^{19}$

Tumor necrosis factor receptor (TNFR)-associated factor 1 (TRAF1) is involved in intracellular signal transduction of a range of TNFR, including CD30 and those associated with nuclear factor- $\kappa \mathrm{B}$ activation. ${ }^{20}$ Assaf et al. studied the expression of TRAF1 using one antibody that recognized 
a formalin-resistant epitope (Ber-TRAF1A). They found strong TRAF1 expression in the tumor cells in most LyP cases, in contrast to tumor cells of primary and secondary pcALCL, in which TRAF1 expression was much more restricted. ${ }^{21}$ Benner et al. also studied this marker in conjunction with MUM1, Bcl2 and CD15, but found it to be of no prognostic or diagnostic utility. ${ }^{22}$ We review the role of apoptosis in LyP pathogenesis in greater depth in the section on pcALCL, below.

Mahtas et al. studied gene deregulation and spatial genome reorganization near the ALCL translocation breakpoint in ALCL. They described the aberrant expression of Fra2 and of Id2 in LyP, the latter being consistent with the findings of Cotta et al. 23,24 They found a lower level of expression in LyP compared with systemic ALCL and argued that gene dosage could be involved in the invasiveness and progression of LyP. ${ }^{23}$

P53 mutations have rarely been found in LyP. Kapur et al. reported two cases of LyP with P53 mutations from an analysis of 11 exons of the P53 gene. They found P53 mutations to be infrequent in cutaneous $\mathrm{CD} 30^{+}$lymphoproliferative disorders, and the two patients with LyP who harbored the mutation did not show any changes in the clinical behavior of the disease. ${ }^{25}$

Notch1 expression has been identified in LyP tumor cells, in which it is associated with the expression of the Notch1 ligand Jagged1, but not of the Delta1 ligand, which was expressed at low or negligible levels. ${ }^{26}$ The levels of expression of Notch1 and Jagged1 were higher in pcALCL samples, a finding that is discussed in greater detail in the section on pcALCL, below.

To date, no ALK fusions have been reported in LyP, in contrast to pcALCL, and no TP63 rearrangements have been found in these patients. $25,27,28$

\section{Primary cutaneous anaplastic large cell lymphoma}

pcALCL is, by definition, a CD30+ large T-cell neoplasm composed of large cells with an anaplastic, pleomorphic or immunoblastic morphology. The CD30 antigen is expressed in more than $75 \%$ of tumor cells. pcALCL resembles other forms of ALCL but arises primarily in the skin. ${ }^{1}$ The clinical course of pcALCL differs from that of systemic forms of ALCL, both $\mathrm{ALK}^{+}$and ALK; which explains why it has been classified as a distinct category. ${ }^{29}$ However, there is some overlap between systemic and primary cutaneous forms of ALCL, whereby they share some molecular alterations, suggesting that other genetic and biological differences are likely to exist and therefore need to be identified. ${ }^{30}$

Primary cutaneous large T-cell lymphoma may also be the result of MF tumor progression. Thus, in patients with pcALCL, a current or previous diagnosis of MF must be excluded. The differential diagnosis between pcALCL and transformed $\mathrm{CD} 30^{+} \mathrm{MF}$ may be challenging, except when there is a clinical presentation with a previous or simultaneous patch-plaque stage MF lesion. Genetic differences between pcALCL and transformed MF have been found using array-based comparative genomic hybridization. ${ }^{31}$ From a clinical point of view, patients with pcALCL typically present with solitary or localized nodules or tumors or, more unusually, papules, with frequent ulceration and rapid evolution in some cases that may simulate aggressive lymphomas. The presence of multiple lesions in $20 \%$ of cases can hinder the differential diagnosis with type $C$ LyP, which features borderline lesions.' This cutaneous lymphoma occurs predominantly in males (male:female ratio $3-2: 1$ ). It is more frequent in people in their sixth decade, but may also appear in childhood. ${ }^{32}$ It has been reported that PCALCL is a common form of cutaneous lymphoma in immunosuppressed patients, such as individuals infected with human immunodeficiency virus and organ transplant recipients. ${ }^{33,34}$ However, in contrast to what usually happens in patients with B-cell lymphomas with CD $30^{+}$large cells, especially in immunosuppressed patients, expression of Epstein-Barr virus by the tumor cells is extremely rare or absent in pcALCL with the T/null cell phenotype. ${ }^{32}$ When it does appear, it is essential to rule out a diagnosis of a B-cell lymphoma with T-cell markers and CD30 expression, such as plasmablastic lymphoma or primary effusion lymphoma.

There is extracutaneous involvement in about $10 \%$ of cases, usually with infiltration of locoregional lymph nodes. In these cases it is important to establish the sequence of presentation in order to rule out cutaneous involvement by systemic ALCL, which has an entirely different prognosis. Characteristically, locoregional lymph node involvement is not related to bad prognosis in pcALCL. Clinical presentation with extensive skin lesions on legs or arms is the only risk factor associated with a statistically significantly worse prognosis $7,35,36$

The classic histological pattern described in pcALCL consists of a circumscribed nodular infiltrate that is mostly dermal, composed of arranged large lymphoid cells and usually with absent or subtle epidermotropism ${ }^{5}$ (Figure 1). However, several variants of this histological pattern have been described, some of which are related to molecular findings described later in this review. ${ }^{5}$ Neutrophils and eosinophils are usually scattered in classic forms, although rich variants, which are usually more common in immunosuppressed patients, have been reported. The presence of this rich granulocytic infiltrate may be explained by the release of interleukin-8, whose levels are elevated in cultured tumor cells and in the serum of these patients. ${ }^{37}$ Other unusual histological presentations of pcALCL have been reported, including angiocentric or angiodestructive forms, ${ }^{3,39}$ subcutaneous and keratoacanthoma-like forms ${ }^{40}$ sarcomatoid variants with prominent spindle-cell morphology, ${ }^{41}$ small cell variants that are rarer than in systemic forms of ALK+ ALCL, ${ }^{42}$ and an intravascular ALCL that may involve the skin and must be distinguished from the more common intralymphatic spread of tumor cells in pcALCL, which seems to have no prognostic implications. ${ }^{43,44}$

pcALCL cells usually carry an activated T-cell phenotype in which CD30 is expressed in more than $75 \%$ of tumor cells (the hallmark of the disease) (Figure 1), frequently accompanied by CD3, CD4 and CD45RO expression and varying degrees of loss of CD5 and CD2. The expression of other activation markers, such as CD71, HLA-DR and CD25 (IL-2R), has been noted in approximately half of the cases. Cytotoxic markers (TIA1, perforin and granzyme B) and cutaneous lymphocyte antigen (CLA, HECA-452) may also be found in around half of the patients. ${ }^{45}$ In contrast to systemic ALKALCL, in which approximately $43 \%$ of cases are $\mathrm{EMA}^{+}{ }^{46}$ EMA is often negative or only focally positive in pcALCL. Interestingly, pcALCL shares with transformed MF and Sézary syndrome the expression of KIR3DL2 
(CD158k) by neoplastic cells, a potential target reviewed in the next section. ${ }^{47}$

Altered expression of the T-cell receptor/CD3 complex, T-cell receptor-associated transcription factors and signal transduction molecules is a common feature of systemic and cutaneous $\mathrm{CD} 30^{+}$lymphoproliferations, a finding that may be of potential diagnostic utility. ${ }^{48}$

Monoclonal rearrangement of the TCR gene occurs in $65 \%$ to $90 \%$ of cases of pcALCL in contrast with a much lower frequency in LyP types A and B. ${ }^{12,49}$

\section{Genetic variants of primary cutaneous anaplastic large cell lymphoma}

pcALCL seems to carry the same molecular alterations as systemic ALCL, but with dramatic differences in frequencies. From the molecular point of view, most pcALCL cases would currently be classified as triple-negative (ALK-, DUSP22-, TP63-negative), since they do not carry any of these precise underlying molecular alterations. However, these lymphomas have an entirely different prognosis from their systemic counterparts, with some of them

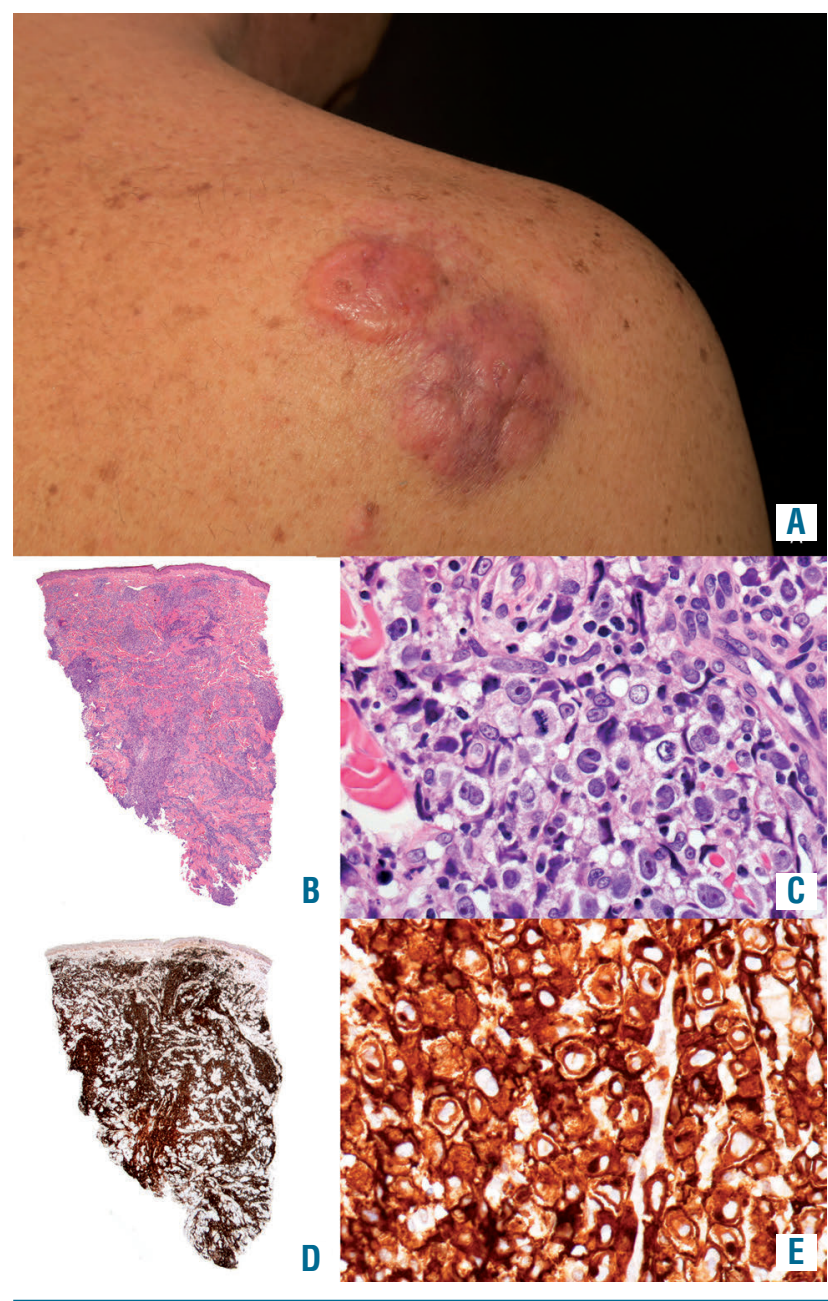

Figure 1. "Classic", ALK-, DUSP22-, TP63- (triple negative) primary cutaneous anaplastic large cell lymphoma. (A) Clinical picture showing two adjacent tumoral erythematous nodules located in the scapular region simulating dermatofibrosarcoma protuberans. (B,C) (x40), Hematoxylin \& eosin stain showing the dermal infiltration consisting of a circumscribed infiltrate, composed of arranged large lymphoid cells with absent or subtle epidermotropism. (D,E) (x40), CD30 stain showing positivity in the membrane and Golgi of the tumoral large cells. showing spontaneous regression and an absence of progression, with long-term survival in the vast majority of the cases (Figure 1). The molecular alterations present in pcALCL are, in descending order of frequency: (i) DUSP22 rearrangements (Figure 2); ${ }^{11,50-61}$ (ii) ALK translocations (Figure 3); ${ }^{62-65}$ (iii) TP63 rearrangements; ${ }^{27,66}$ and (iv) NPM1TYK2 gene fusion. ${ }^{67-69}$ ALK translocations are much less frequent than in systemic lymphomas, having been described in isolated cases or very small series. ${ }^{63-65}$ TP63 rearrangements and NPM1-TYK2 gene fusion are exceptional and only isolated cases have been reported. ${ }^{27,67-69}$

ALK-negative primary cutaneous anaplastic large cell lymphoma with DUSP22 rearrangements

DUSP22 rearrangements in systemic ALK- ALCL have been associated with a better prognosis, similar to that of $\mathrm{ALK}^{+}$systemic ALCL, compared with TP63-translocated or triple-negative cases. ${ }^{50,51}$ About $20 \%$ of pcALCL cases harbor the DUSP22-IRF4 translocation, with no correlation with MUM1/IRF4 protein expression..$^{11,52,53}$ First reported in LyP, a particular biphasic histological pattern has been linked to the presence of DUSP22 rearrangements in pcALCL (Figure 2). This pattern is characterized
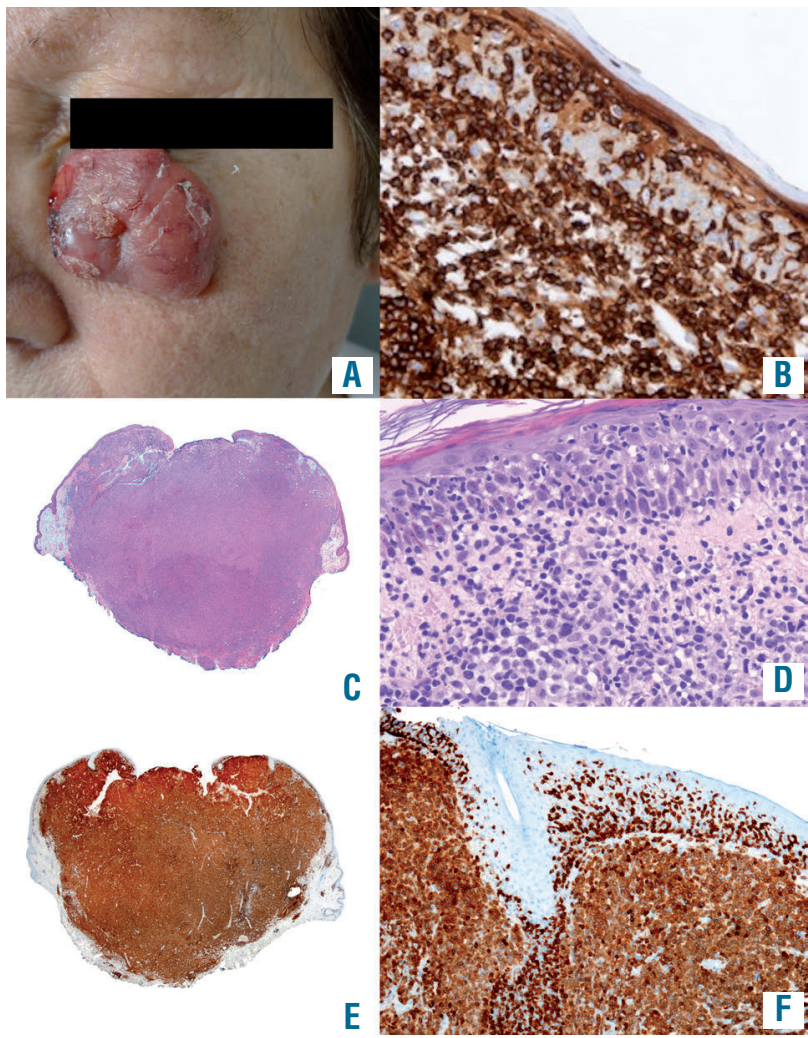

Figure 2. ALK-negative primary cutaneous anaplastic large cell lymphoma with DUSP22 rearrangements. (A) Clinical picture of a large ulcerated tumor in the left malar region of an elderly woman showing (B) the typical CD30 staining of a case of pcALCL with DUSP22 rearrangement (Ref. 58, courtesy of Onaindia et al.), evidencing extensive epidermotropism with $\mathrm{CD} \mathrm{O}^{+}$small-to-mediumsized T-lymphocytes that simulate pagetoid reticulosis lesions. (C) Hematoxylin $\&$ eosin-stained panoramic view of the case in (E) and $(F)$ showing the tumor nodule with profuse dermal involvement. (D) Detail, stained with hematoxylin \& eosin, of another case exemplifying the biphasic epidermal and dermal lymphocytic infiltrate. (E,F) (x40), CD3 stain highlights the intraepidermic neoplastic cells in another case with DUSP22 rearrangement. 
by the simultaneous presence of dermic CD30+ large cells and intraepidermal infiltrate by $\mathrm{CD} 0^{+}$small cells with a pagetoid reticulosis pattern. ${ }^{10,54}$ The clinical behavior and prognosis of cases with DUSP22 rearrangements is similar to that of cases without such rearrangements. ${ }^{55}$ Currently, clinical presentation and staging remain essential to differentiate cases of pcALCL with DUSP22 rearrangement from LyP with this molecular alteration, because the two entities have similar histological features. ${ }^{54}$ DUSP22 rearrangements have also been described in rare cases of CD30-rich tumoral MF.56

Expression of the chemokine receptor gene CCR8 is associated with DUSP22 rearrangements in ALCL. ${ }^{57}$ It has been proposed that the higher level of expression of this skinhoming chemokine receptor may explain the lower tendency of pcALCL to disseminate to extracutaneous sites. ${ }^{58}$

The pathways activated after DUSP22-IRF4 rearrangements in peripheral T-cell lymphomas have recently been investigated by Mélard et al..$^{59}$ They found a tumor suppressor function for DUSP22, with the restored expression of DUSP22 promoting apoptosis and impairing soft agar clonogenicity. ${ }^{59}$ Negative regulation of the interleukin6/leukemia inhibitory factor/signal transduction and activator of transcription (STAT)-3 pathway has been found in

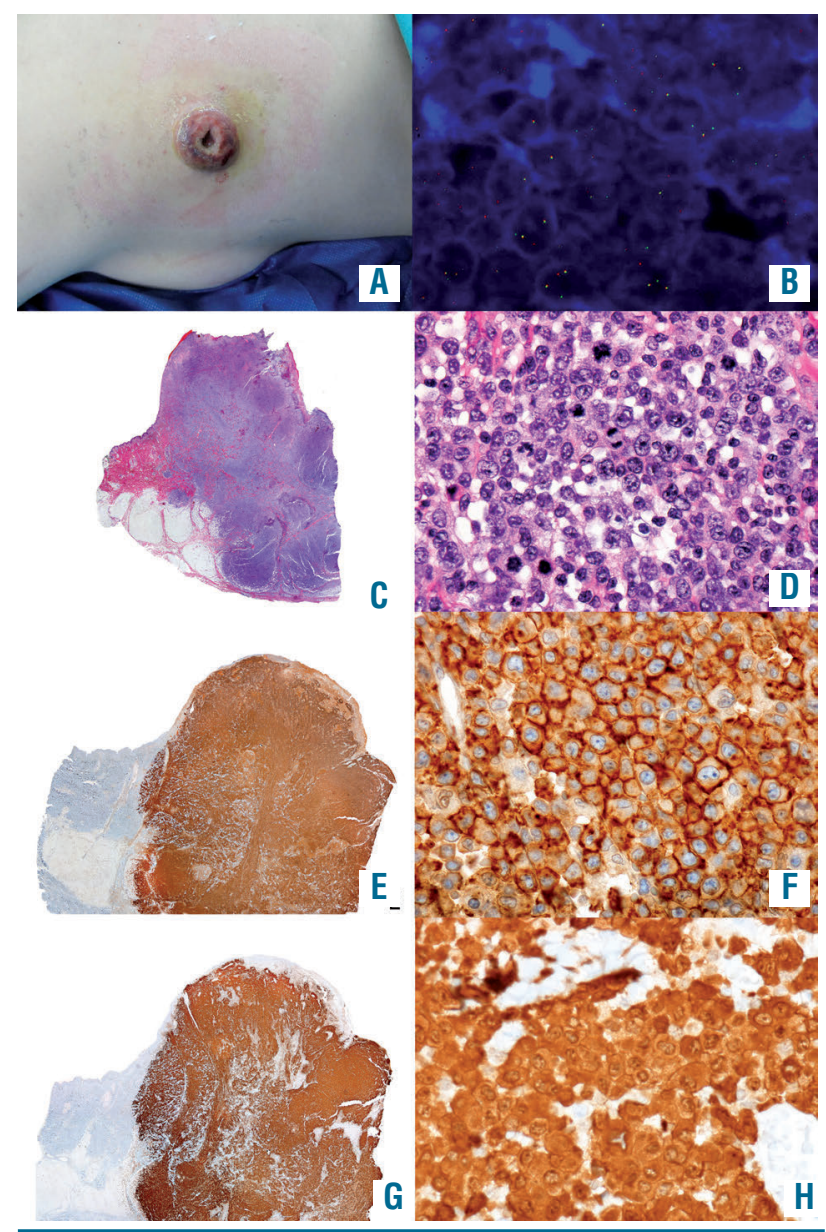

Figure 3. ALK-positive primary cutaneous anaplastic large cell lymphoma. (A) Clinical picture of a large ulcerated tumor located on the back. (B) Fluorescence in situ hybridization image showing an ALK reciprocal translocation with gain of one or two copies of the ALK gene. (C,D) Hematoxylin \& eosin stain showing the morphology of large T cells (E,F) (x40), with CD30 positivity and $(G, H)(x 40)$, nuclear and cytoplasmic ALK positivity in tumor T cells. experimental studies. ${ }^{60}$ Consistent with these findings, DUSP22 (also known as JKAP) knockout mice develop inflammation and autoimmunity. ${ }^{61}$

\section{ALK-positive primary cutaneous anaplastic large cell lymphoma}

Cutaneous involvement in cases of systemic ALK+ $\mathrm{ALCL}$ is generally indicative of a bad prognosis (relative risk: 2) and occurs in $26 \%$ of pediatric ALK ${ }^{+}$ALCL cases. ${ }^{6}$ In contrast, $\mathrm{ALK}^{+}$pcALCL cases seem to have a more favorable outcome. Only a few cases of $\mathrm{ALK}^{+}$pcALCL have been reported, the largest series being that described by Oschlies et al. ${ }^{63}$ in which six pediatric patients with $\mathrm{ALK}^{+}$pcALCL had a favorable clinical course, comparable to that of patients with $\mathrm{ALK}^{-}$pcALCL. Other $\mathrm{ALK}^{+}$primary cutaneous cases occurred in adults and had peculiar features, such as cytoplasmic ALK expression and a lack of ALK translocation. ${ }^{64}$ To date, no ALK fusion partners exclusive to the primary cutaneous cases have been reported. It is important to stage patients with $\mathrm{ALK}^{+}$pcALCL carefully because cutaneous lesions triggered by insect bites can be the first manifestation of systemic $\mathrm{ALK}^{+}$ALCL. ${ }^{65}$ The authors postulated that insect bite-associated antigens may attract T lymphocytes to the skin, some of which bear the $A L K$ translocation $\mathrm{t}(2 ; 5)$. The subsequent release of different cytokines at the site of the bite could act as a "second hit" and activate T cells, which may express the oncogenic NPM-ALK protein and initiate deregulated growth. ${ }^{65}$

\section{Primary cutaneous anaplastic large cell lymphoma with TP63 rearrangements}

In 2012, Vasmatzis et al. described two of 19 pcALCL that carried TP63 rearrangements, ${ }^{27}$ both of which had an unusual, aggressive clinical behavior, analogous to that of systemic ALCL with TP63 rearrangements. ${ }^{51}$ Subsequent work by the same group also identified a case of aggressive MF with a TP63 translocation. ${ }^{66}$ In both series, TP63 translocations were associated with strong TP63 protein expression detectable by immunohistochemistry, but this was not a specific finding since the protein was also expressed in cases without a TP63 translocation. Schrader et al. reviewed a series of 17 cases of aggressive LyP and pcALCL. They found no cases with a TP63 translocation, and confirmed the lack of specificity of the TP63 immunohistochemistry. ${ }^{28}$

\section{NPM1-TYK2 gene fusion and oncogenic STAT3 activation}

Mutations on the JAK1/STAT3 pathway are common in systemic ALK- ALCL. ${ }^{67,68}$ However, these mutations have been found in only $5 \%$ of pcALCL, which is further evidence of the distinct molecular pathogenesis of the two entities. Whole-transcriptome sequencing done in pcALCL revealed the NPM1-TYK2 gene fusion, which encodes a protein containing an intact catalytic domain in TYK2 and an oligomerization domain of NPM. It was present in two (1 LyP, 1 pcALCL) of the cases of primary cutaneous $\mathrm{CD} 0^{+}$lymphoproliferative disorders studied $(n=47)$ and was not found in other mature T-cell neoplasms $(\mathrm{n}=151)$. Both cases showed nuclear STAT5 expression. This defective kinase activates the STAT signaling pathway (STAT1/3/5), implying that TYK2 could be a therapeutic target in this subset of patients. ${ }^{69}$

\section{Epigenetic abnormalities in primary cutaneous anaplastic large cell lymphoma}

Epigenetic abnormalities, including histone tail posttranslational modifications and DNA methylation, are a 
hallmark of cancer and a potential target for therapy. ${ }^{70}$ DNA methylation profiling studies have not been done specifically in cutaneous ALCL; data derived from the analysis of systemic ALCL show an ALK-independent methylation signature, characteristic of and different from that of other peripheral T-cell lymphomas, establishing a relation with the promoter DNA methylation of early $\mathrm{T}$ cell stages. ${ }^{71}$

The enhancer of the zeste homolog 2 (EZH2) constitutes the core catalytic subunit of polycomb repressive complex2 (PRC2) and has a "canonical" function as a PRC2-dependent lysine 27 of the histone H3 (H3K27) methylator, which can also methylate a number of nonhistone proteins, thereby promoting transcriptional activation, and making it a potential therapeutic target. ${ }^{72}$ Yi et al. found EZH2 overexpression in pcALCL and large cell transformed cutaneous T-cell lymphomas, in which it regulates apoptosis, cell-cycling in the neoplastic cells, and the interaction between the tumor and its microenvironment. $^{73}$

Non-coding RNA play an important epigenetic regulatory role that has implications for cell development and cancer, above all in the pathogenesis of T-cell lymphomas. ${ }^{74}$ MicroRNA (miRNA, miR) are small, non-coding RNA molecules that regulate gene expression at the post-transcriptional level by targeting the 3'-untranslated regions of messenger RNA to promote their degradation or decrease their translation. ${ }^{75}$ Several studies have identified different miRNA signatures for CD30+ pcALCL. ${ }^{62,76-78}$ Benner et al. showed upregulation of an oncogenic miRNA signature in pcALCL comprising miR-155, miR-27b, miR-30c and miR29. ${ }^{77}$ Sandoval's study confirmed the upregulation of miR155 and identified upregulation of miR-21, miR-1423p/5p, let-7i, miR-424, miR-431, miR-542-5p, miR-29b-1, miR-342-p, and miR-484, with downregulation of some interesting tumor-suppressor miRNA such as miR23b/miR-27b, miR-203, miR-205 and miR-125b. ${ }^{78}$ This miRNA profile reported for pcALCL differs considerably from those reported in systemic ALCL, which suggests a different underlying pathogenic mechanism or reflects differences in the microenvironment ${ }^{79,80}$

In this setting, epigenetic therapy (histone deacetylase inhibitors, such as romidepsin or belinostat, and methylation inhibitors) has shown some benefit in the treatment of ALCL and cutaneous T-cell lymphomas., ${ }^{81,82}$ In the future, more precise identification of miRNA profiling in pcALCL could allow us to develop specific diagnostic and progression markers and may lead to the use of more specific targeted therapies.

\section{NOTCH signaling in primary cutaneous anaplastic large cell lymphoma}

The deregulation of Notch signaling in hematopoietic cells has been linked to the development of several hematologic malignancies, including acute lymphoblastic T-cell leukemia, B-cell chronic lymphocytic leukemia, multiple myeloma, acute myeloid leukemia, Hodgkin lymphoma and systemic ALCL. ${ }^{83-88}$ Increased expression of Notch signaling molecules has been described in primary cutaneous $\mathrm{CD} 30^{+}$lymphoproliferative disorders, as previously mentioned. ${ }^{26}$ The same group found that pcALCL cells increased their expression of the intracellular domains of Notch receptors Notch1, Notch2, Notch3 and Notch4, as well as of the Notch ligand Delta and the product HES1. ${ }^{89}$ In addition, it was demonstrated that the inhibition of the
Notch pathway through inhibition of gamma-secretase with gamma-secretase inhibitors induces apoptosis and decreases cell viability in pcALCL cell lines, findings that identify the Notch pathway as a potential therapeutic target in PcALCL. ${ }^{89}$

\section{CDKN2A-CDKN2B losses in primary cutaneous anaplastic large cell lymphoma}

The CDKN2A-CDKN2B locus on the 9p21 chromosomal band encodes the proteins p14ARF, p16INK4A and p15INK4B. p14ARF-mdm2-p53 and p16INK4A/ p15INK4B-Rb1 pathways are important for controlling the cell cycle, especially progression between $\mathrm{G} 1$ and $\mathrm{S}$ phases. ${ }^{90}$ Combined CDKN2A-CDKN2B deletion has been linked to aggressive behavior in cutaneous T-cell lymphomas, ${ }^{91-95}$ but more rarely in pcALCL, as confirmed by two research groups. ${ }^{95,96}$

\section{Other cytogenetic abnormalities in primary cutaneous anaplastic large cell lymphoma}

Additional chromosomal alterations, such as gains of $7 q 31$ and losses on 6q16-6q21, 6q27 and 13q34 regions, are recurrently present in pcALCL. ${ }^{31,62,97}$ Interestingly, these alterations in pcALCL occur mainly in telomeric and centromeric regions. Genomic imbalances have been found in chromosomal regions coding for FGFR1 (8p11), NRAS (1p13.2), MYCN (2p24.1), RAF1 (3p25) and others. ${ }^{98}$

\section{Targeted therapies for primary cutaneous CD30-positive lymphoproliferative disorders}

Currently, complete surgical excision and local radiotherapy are the recommended first-line therapies for solitary or grouped localized pcALCL lesions. ${ }^{99}$ However, the most appropriate treatment in the relapsed/refractory setting has not been clearly identified. Multiagent chemotherapy is customarily indicated for extracutaneous tumor spread beyond locoregional lymph nodes. In recent years, brentuximab vedotin, an anti-CD30 antibody-drug conjugate has been proposed as one of the best options for achieving complete remission with low toxicity in these patients. ${ }^{100}$ ALCANZA, an international, open-label, randomized, phase 3 , multicenter clinical trial, has shown significant improvement in objective responses lasting at least 4 months with brentuximab vedotin compared with the physician's choice of methotrexate or bexarotene in $\mathrm{CD}^{+} 0^{+}$cutaneous $\mathrm{T}$-cell lymphomas, especially $\mathrm{MF}$ and pcALCL (having excluded Sézary syndrome and LyP from the study, since these are entities in which brentuximab vedotin is successful). ${ }^{101}$ The mean duration of response to this drug in pcALCL is 7.6 months. Peripheral neuropathy and fatigue are the most commonly reported adverse events (in $57.2 \%$ and $35.6 \%$ of cases, respectively). ${ }^{102}$ Recently the US Food and Drug Administration and the European Medicines Agency approved the use of brentuximab vedotin in cutaneous T-cell lymphomas.

Besides the use of anti-CD30 molecules in the treatment of primary cutaneous $\mathrm{CD}^{+} 0^{+}$lymphoproliferative disorders, molecular data generated in the study of pcALCL offer multiple opportunities for targeted therapies (Figure 4).

The recognition of convergent mutations and kinase fusions leading to STAT3 activation in a subgroup of pcALCL could allow the use of JAK $1 / 2 / 3$ inhibitors in the 


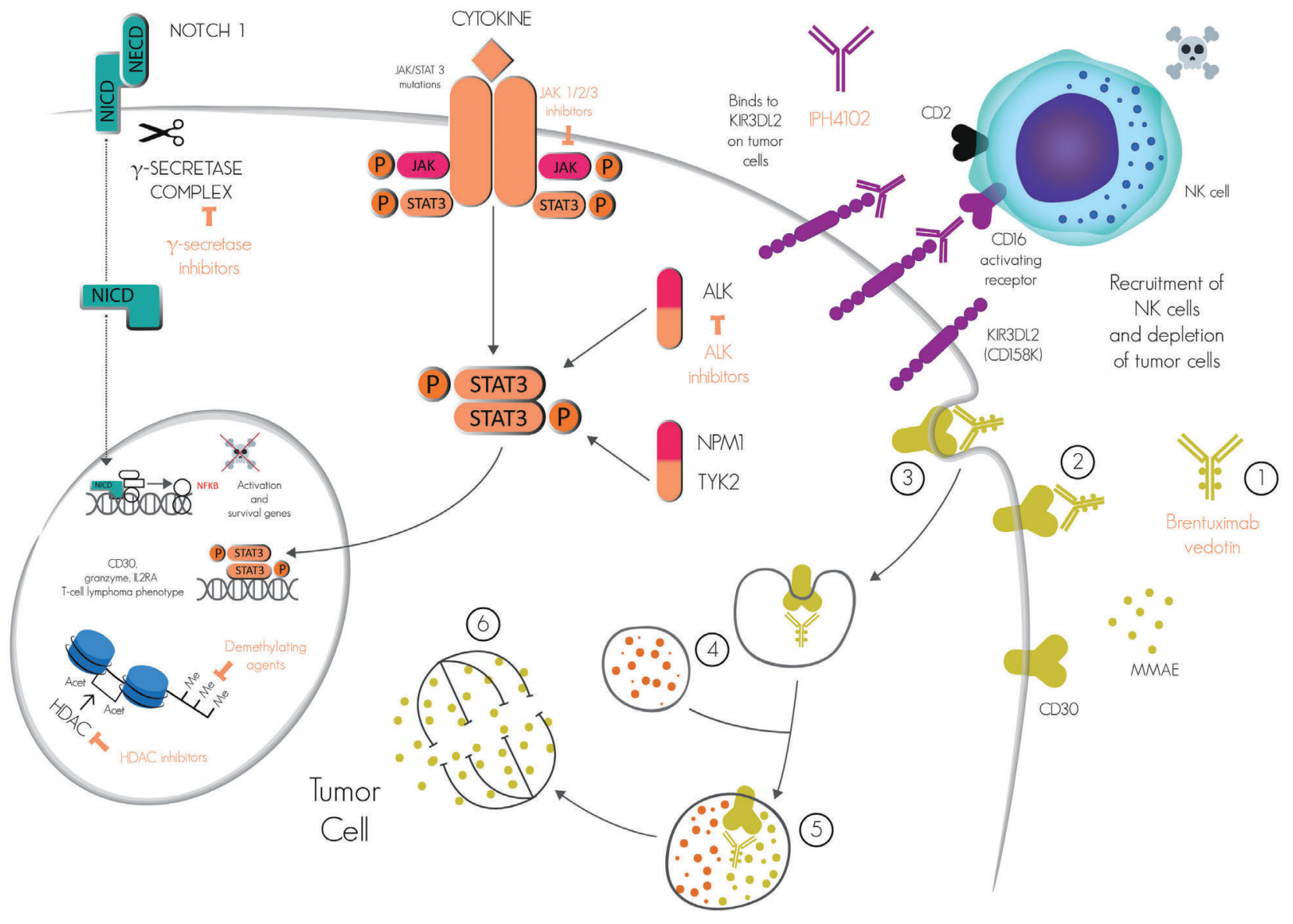

Figure 4. New targeted therapies in advanced primary cutaneous anaplastic large cell lymphoma. Brentuximab vedotin is a drug composed of a chimeric anti-CD30 antibody linked to four monomethyl auristatin (MMAE) molecules (on average) (1). This antibody-drug conjugate first binds to CD30 on the surface of pcALCL cells (2). It is then internalized by a receptor-mediated endocytosis process ( 3 and 4). The resultant vesicle fuses with lysosomes (4), leading to proteolytic cleavage of the dipeptide linker and the presence of free MMAE molecules, which inhibit tubulin polymerization of the cellular cytoskeleton and arrest growth of pcALCL tumor cells. Gamma-secretase ( $\gamma$-secretase) inhibitors prevent release of intracellular NOTCH1 (ICN1) from membrane-tethered heterodimeric NOTCH1 protein. This causes the downregulation of the tumor cell nuclear factor-KB (NFKB) pathway and the inactivation of survival genes. JAK1/2/3 inhibitors are effective in vitro for controlling pcALCL cell growth. This mechanism involves oncogenic JAK1 or STAT3 mutations associated with the hyperactive pSTAT3 shown in pcALCL with an NPM1-TYK2 gene fusion and oncogenic STAT3 activation. In addition, anti-ALK molecules such as crizotinib, alectinib, and ceritinib in pcALCL patients with ALK rearrangements could downregulate the STAT3 pathway, ultimately inducing tumor-cell death. IPH4102 is a humanized monoclonal antibody directed against the cellular receptor KIR3DL2 (CD158K). This receptor has been shown to be aberrantly expressed in advanced pcALCL. IPH4140 targets KIR3DL2 in tumor cells and promotes cell lysis after linking to the CD16 activating receptor through antibody-dependent, cell-derived cytotoxicity mediated by NK cells. At the epigenetic level, histone deacetylase (HDAC) inhibitors and demethylating agents have demonstrated a degree of effectiveness at inducing cell-cycle arrest, differentiation and/or apoptosis of tumor cells.

treatment of this subgroup. ${ }^{68,103}$ In addition, patients with the rare subtype of $\mathrm{ALK}^{+}$pcALCL could benefit from therapy with the ALK kinase inhibitor crizotinib, and other new-generation inhibitors such as alectinib or ceritinib. ${ }^{104}$

KIR3DL2 (CD158K) is a killer cell immunoglobulin-like receptor normally expressed by minor subsets of circulating $\mathrm{CD}^{+}$lymphocytes and natural killer cells. ${ }^{105}$ In contrast, tumor cells of pcALCL and CD30+ lymphoproliferative disorders, which are derived from cell lines Mac2a and Mac2b, express KIR3DL2 strongly. ${ }^{105}$ In Sézary syndrome, the expression of KIR3DL2 in malignant blood cells has been proposed as a marker of blood tumor burden. ${ }^{106}$ The novel agent IPH4102 is a monoclonal antibody directed against KIR3DL2 that has proven effective in in vitro cell lines of advanced pcALCL. ${ }^{47}$

The NOTCH pathway is activated in pcALCL as a consequence of various mutations. ${ }^{89}$ Deregulated activity of the NOTCH pathway can be inhibited using gamma secretase inhibitors, as has been shown in an in vitro experiment. $^{89}$
Finally, therapies acting at the epigenetic level, based on the mutations and epigenetic alterations described above, could be useful in pcALCL. More specifically, romidepsin and vorinostat, inhibitors of histone deacetylase, derived from the bacterium Chromobacterium violaceum are effective at inducing apoptosis with an antitumor effect in cutaneous T-cell lymphomas, alone and in combination. ${ }^{107,108}$ Recently, researchers from the Yale School of Medicine, using cell lines derived from patients with advanced MF and Sézary syndrome (MyLa, Sez4, HH, Hut78), observed in vitro that bromodomain and extraterminal (BET) protein inhibitors are synergistically potentiated by BCL2 inhibitors (e.g., venetoclax) and histone deacetylase inhibitors (e.g., vorinostat and romidepsin) in cutaneous T-cell lymphomas with $M Y C$ oncogene amplification. ${ }^{109}$ Patients with cutaneous CD30+ lymphoproliferative disorders with $M Y C$-induced Id2 overexpression could also be candidates for this therapy. ${ }^{24}$

Recently, it was proposed that miR-155 inhibition could be used in combination with apoptotic treatments 
and checkpoint inhibitors in MF patients. ${ }^{110} \mathrm{MiR}-155$ is also upregulated in pcALCL, ${ }^{77}$ providing an additional therapeutic opportunity for these tumors.

\section{Acknowledgments}

Amaia Alzelai, Salma Machan, Victor Alegre and David Lapeña provided cases and inspiration.

\section{Funding}

This work was supported by grants from the Instituto de Salud Carlos III (ISCIII) of the Spanish Ministry of Economy and Competence (MINECO, RTICC ISCIII and CIBERONC) (SAF2013-47416-R, RD06/0020/0107-RD012/0036/0060 and Plan Nacional I+D+I: PI17/2172, PI16/01294 and PIE15/0081), AECC and the Madrid Autonomous Community.

\section{References}

1. Swerdlow SH, Campo E, Pileri SA, et al. The 2016 revision of the World Health Organization classification of lymphoid neoplasms. Blood. 2016;127(20):2375-2390.

2. Taylor J, Xiao W, Abdel-Wahab O. Diagnosis and classification of hematologic malignancies on the basis of genetics. Blood. 2017;130(4):410-423

3. Macaulay WL. Lymphomatoid papulosis. A continuing self-healing eruption, clinically benign--histologically malignant. Arch Dermatol. 1968:97(1):23-30.

4. Nijsten T, Curiel-Lewandrowski C, Kadin ME. Lymphomatoid papulosis in children: a retrospective cohort study of 35 cases. Arch Dermatol. 2004;140(3):306-312.

5. Kempf W. A new era for cutaneous CD30positive T-cell lymphoproliferative disorders. Semin Diagn Pathol. 2017;34(1):22-35.

6. Kempf W, Mitteldorf C, Karai LJ, et al. Lymphomatoid papulosis - making sense of the alphabet soup: a proposal to simplify terminology. J Dtsch Dermatol Ges. 2017;15(4):390-394.

7. Bekkenk MW, Geelen FA, van Voorst Vader PC, et al. Primary and secondary cutaneous CD30(+) lymphoproliferative disorders: a report from the Dutch Cutaneous Lymphoma Group on the long-term followup data of 219 patients and guidelines for diagnosis and treatment. Blood. 2000;95(12):3653-3661.

8. Saggini A, Gulia A, Argenyi Z, et al. A variant of lymphomatoid papulosis simulating primary cutaneous aggressive epidermotropic CD8+ cytotoxic T-cell lymphoma. Description of 9 cases. Am J Surg Pathol. 2010;34(8):1168-1175.

9. Kempf W, Kazakov DV, Scharer L, et al. Angioinvasive lymphomatoid papulosis: a new variant simulating aggressive lymphomas. Am J Surg Pathol. 2013;37(1):1-13.

10. Karai LJ, Kadin ME, Hsi ED, et al. Chromosomal rearrangements of $6 \mathrm{p} 25.3$ define a new subtype of lymphomatoid papulosis. Am J Surg Pathol. 2013;37(8): 1173-1181

11. Wada DA, Law ME, Hsi ED, et al. Specificity of IRF4 translocations for primary cutaneous anaplastic large cell lymphoma: a multicenter study of 204 skin biopsies. Mod Pathol. 2011;24(4):596-605.

12. Greisser J, Palmedo G, Sander C, et al. Detection of clonal rearrangement of T-cell receptor genes in the diagnosis of primary cutaneous CD30 lymphoproliferative disorders. J Cutan Pathol. 2006;33(11):711-715.

13. Chott A, Vonderheid EC, Olbricht S, et al. The dominant $\mathrm{T}$ cell clone is present in multiple regressing skin lesions and associated $\mathrm{T}$ cell lymphomas of patients with lymphomatoid papulosis. I Invest Dermatol. 1996;106(4):696-700.

14. de la Garza Bravo MM, Patel KP, Loghavi S, et al. Shared clonality in distinctive lesions of lymphomatoid papulosis and mycosis fungoides occurring in the same patients suggests a common origin. Hum Pathol. 2015;46(4):558-569

15. Rodriguez-Pinilla SM, Ortiz-Romero PL, Monsalvez V, et al. TCR-gamma expression in primary cutaneous T-cell lymphomas. Am J Surg Pathol. 2013;37(3):375-384

16. Yasui D, Miyano M, Cai S, et al. SATB1 targets chromatin remodelling to regulate genes over long distances. Nature. 2002:419(6907):641-645.

17. Alvarez JD, Yasui DH, Niida $\mathrm{H}$, et al. The MAR-binding protein SATB1 orchestrates temporal and spatial expression of multiple genes during T-cell development. Genes Dev. 2000;14(5):521-535.

18. Wang Y, Su M, Zhou LL, et al. Deficiency of SATB1 expression in Sezary cells causes apoptosis resistance by regulating FasL/CD95L transcription. Blood. 2011;117 (14):3826-3835

19. Sun J, Yi S, Oiu L, et al. SATB1 defines a subtype of cutaneous CD30(+) lymphoproliferative disorders associated with a T-helper 17 cytokine profile. J Invest Dermatol. 2018;138(8):1795-1804

20. Durkop H, Hirsch B, Hahn C, et al. Differential expression and function of A2O and TRAF1 in Hodgkin lymphoma and anaplastic large cell lymphoma and their induction by $\mathrm{CD} 30$ stimulation. J Pathol. 2003;200(2):229-239.

21. Assaf C, Hirsch B, Wagner F, et al. Differential expression of TRAF1 aids in the distinction of cutaneous CD30-positive lymphoproliferations. J Invest Dermatol. 2007;127(8):1898-1904.

22. Benner MF, Jansen PM, Meijer CJ, et al. Diagnostic and prognostic evaluation of phenotypic markers TRAF1, MUM1, BCL2 and CD15 in cutaneous CD30-positive lymphoproliferative disorders. Br J Dermatol. 2009;161(1):121-127.

23. Mathas S, Kreher S, Meaburn KJ, et al. Gene deregulation and spatial genome reorganization near breakpoints prior to formation of translocations in anaplastic large cell lymphoma. Proc Natl Acad Sci USA. 2009;106 (14):5831-5836

24. Cotta CV, Leventaki V, Atsaves V, et al. The helix-loop-helix protein Id2 is expressed differentially and induced by Myc in T-cell lymphomas. Cancer. 2008;112(3):552-561.

25. Kapur S, Tiemann M, Menke MA, et al. The role of $p 53$ and anaplastic lymphoma kinase genes in the progression of cutaneous CD30(+) lymphoproliferative diseases. Indian J Med Res. 2005;121(1):46-54.
26. Kamstrup MR, Ralfkiaer E, Skovgaard GL, et al. Potential involvement of Notch1 signalling in the pathogenesis of primary cutaneous CD30-positive lymphoproliferative disorders. Br J Dermatol. 2008;158(4):747753

27. Vasmatzis G, Johnson SH, Knudson RA, et al. Genome-wide analysis reveals recurrent structural abnormalities of TP63 and other p53-related genes in peripheral T-cell lymphomas. Blood. 2012;120(11):2280-2289.

28. Schrader AM, Chung YY, Jansen PM, et al. No TP63 rearrangements in a selected group of primary cutaneous $\mathrm{CD} 30+$ lymphoproliferative disorders with aggressive clinical course. Blood. 2016;128(1):141-143.

29. Fornari A, Piva R, Chiarle R, et al. Anaplastic large cell lymphoma: one or more entities among T-cell lymphoma? Hematol Oncol. 2009;27(4):161-170

30. Xing X, Feldman AL. Anaplastic large cell lymphomas: ALK positive, ALK negative, and primary cutaneous. Adv Anat Pathol. 2015;22(1):29-49.

31. Laharanne E, Oumouhou N, Bonnet F, et al. Genome-wide analysis of cutaneous T-cell lymphomas identifies three clinically relevant classes. J Invest Dermatol. 2010;130(6): 1707-1718.

32. Stein H, Foss HD, Durkop H, et al. CD30(+) anaplastic large cell lymphoma: a review of its histopathologic, genetic, and clinical features. Blood. 2000;96(12):3681-3695.

33. Kerschmann RL, Berger TG, Weiss LM, et al. Cutaneous presentations of lymphoma in human immunodeficiency virus disease. Predominance of $\mathrm{T}$ cell lineage. Arch Dermatol. 1995;131(11):1281-1288.

34. Yurtsever H, Kempf W, Laeng RH. Posttransplant CD30+ anaplastic large cell lymphoma with skin and lymph node involvement. Dermatology. 2003;207(1): 107-110.

35. Benner MF, Willemze R. Applicability and prognostic value of the new TNM classification system in 135 patients with primary cutaneous anaplastic large cell lymphoma. Arch Dermatol. 2009;145(12):1399-1404.

36. Woo DK, Jones CR, Vanoli-Storz MN, et al. Prognostic factors in primary cutaneous anaplastic large cell lymphoma: characterization of clinical subset with worse outcome. Arch Dermatol. 2009:145(6):667-674.

37. Burg G, Kempf W, Kazakov DV, et al. Pyogenic lymphoma of the skin: a peculiar variant of primary cutaneous neutrophilrich CD30+ anaplastic large-cell lymphoma. Clinicopathological study of four cases and review of the literature. Br J Dermatol. 2003;148(3):580-586

38. Massone C, El-Shabrawi-Caelen L, Kerl H, et al. The morphologic spectrum of primary cutaneous anaplastic large T-cell lymphoma: a histopathologic study on 66 biopsy speci- 
mens from 47 patients with report of rare variants. J Cutan Pathol. 2008;35(1):46-53.

39. Kempf W, Kazakov DV, Paredes BE, et al. Primary cutaneous anaplastic large cell lymphoma with angioinvasive features and cytotoxic phenotype: a rare lymphoma variant within the spectrum of CD30+ lymphoproliferative disorders. Dermatology. 2013; 227(4):346-352.

40. Resnik KS, Kutzner H. Of lymphocytes and cutaneous epithelium: keratoacanthomatous hyperplasia in CD30+ lymphoproliferative disorders and CD30+ cells associated with keratoacanthoma. Am J Dermatopathol. 2010;32(3):314-315.

41. Wang J, Sun NC, Nozawa Y, et al. Histological and immunohistochemical characterization of extranodal diffuse largecell lymphomas with prominent spindle cell features. Histopathology. 2001;39(5):476481.

42. Kinney MC, Collins RD, Greer JP, et al. A small-cell-predominant variant of primary Ki-1 (CD30)+ T-cell lymphoma. Am J Surg Pathol. 1993;17(9):859-868.

43. Wang L, Li C, Gao T. Cutaneous intravascular anaplastic large cell lymphoma. J Cutan Pathol. 2011;38(2):221-226.

44. Ferrara G, Ena L, Cota C, et al. Intralymphatic spread is a common finding in cutaneous CD30+ lymphoproliferative disorders. Am J Surg Pathol. 2015;39(11): 1511-1517.

45. Felgar RE, Macon WR, Kinney MC, et al. TIA-1 expression in lymphoid neoplasms. Identification of subsets with cytotoxic T lymphocyte or natural killer cell differentiation. Am J Pathol. 1997;150(6):1893-1900

46. Savage KJ, Harris NL, Vose JM, et al. ALKanaplastic large-cell lymphoma is clinically and immunophenotypically different from both ALK+ ALCL and peripheral T-cell lymphoma, not otherwise specified: report from the International Peripheral T-Cell Lymphoma Project. Blood. 2008;111(12): 5496-5504.

47. Battistella M, Janin A, Jean-Louis F, et al. KIR3DL2 (CD158k) is a potential therapeutic target in primary cutaneous anaplastic large-cell lymphoma. Br J Dermatol. 2016; 175(2):325-333

48. Geissinger E, Sadler P, Roth S, et al. Disturbed expression of the T-cell receptor/CD3 complex and associated signaling molecules in CD30+ T-cell lymphoproliferations. Haematologica. 2010;95(10):1697-1704.

49. Macgrogan G, Vergier B, Dubus $P$, et al. CD30-positive cutaneous large cell lymphomas. A comparative study of clinicopathologic and molecular features of 16 cases. Am J Clin Pathol. 1996;105(4):440450.

50. Feldman AL, Dogan A, Smith DI, et al. Discovery of recurrent $t(6 ; 7)(p 25.3 ; q 32.3)$ translocations in ALK-negative anaplastic large cell lymphomas by massively parallel genomic sequencing. Blood. 2011;117(3): 915-919.

51. Parrilla Castellar ER, Jaffe ES, Said JW, et al. ALK-negative anaplastic large cell lymphoma is a genetically heterogeneous disease with widely disparate clinical outcomes. Blood. 2014;124(9):1473-1480.

52. Feldman AL, Law M, Remstein ED, et al. Recurrent translocations involving the IRF4 oncogene locus in peripheral T-cell lymphomas. Leukemia. 2009;23(3):574-580

53. Kiran T, Demirkesen C, Eker C, et al. The significance of MUM1/IRF4 protein expression and IRF4 translocation of CD30(+) cutaneous T-cell lymphoproliferative disorders: a study of 53 cases. Leuk Res. 2013;37 (4):396-400

54. Onaindia A, Montes-Moreno S, RodriguezPinilla SM, et al. Primary cutaneous anaplastic large cell lymphomas with $6 \mathrm{p} 25.3$ rearrangement exhibit particular histological features. Histopathology. 2015;66(6):846855.

55. Fauconneau A, Pham-Ledard A, Cappellen $D$, et al. Assessment of diagnostic criteria between primary cutaneous anaplastic large-cell lymphoma and CD30-rich transformed mycosis fungoides; a study of 66 cases. Br J Dermatol. 2015;172(6):1547-1554.

56. Pham-Ledard A, Prochazkova-Carlotti M, Laharanne $\mathrm{E}$, et al. IRF4 gene rearrangements define a subgroup of CD30-positive cutaneous T-cell lymphoma: a study of 54 cases. J Invest Dermatol. 2010;130(3):816825.

57. Xing X, Flotte TJ, Law ME, et al. Expression of the chemokine receptor gene, CCR8, is associated With DUSP22 rearrangements in anaplastic large cell lymphoma. Appl Immunohistochem Mol Morphol. 2015;23 (8):580-589.

58. van Kester MS, Tensen CP, Vermeer MH, et al. Cutaneous anaplastic large cell lymphoma and peripheral T-cell lymphoma NOS show distinct chromosomal alterations and differential expression of chemokine receptors and apoptosis regulators. J Invest Dermatol. 2010;130(2):563-575.

59. Melard P, Idrissi Y, Andrique L, et al. Molecular alterations and tumor suppressive function of the DUSP22 (Dual specificity phosphatase 22) gene in peripheral T-cell lymphoma subtypes. Oncotarget. 2016;7(42):68734-68748.

60. Sekine Y, Tsuji S, Ikeda O, et al. Regulation of STAT3-mediated signaling by LMWDSP2. Oncogene. 2006;25(42):5801-5806.

61. Li JP, Yang CY, Chuang HC, et al. The phosphatase JKAP/DUSP22 inhibits T-cell receptor signalling and autoimmunity by inactivating Lck. Nat Commun. 2014:5:3618.

62. Le Deley MC, Reiter A, Williams D, et al. Prognostic factors in childhood anaplastic large cell lymphoma: results of a large European intergroup study. Blood. 2008;111(3):1560-1566.

63. Oschlies I, Lisfeld J, Lamant L, et al. ALKpositive anaplastic large cell lymphoma limited to the skin: clinical, histopathological and molecular analysis of 6 pediatric cases. A report from the ALCL99 study. Haematologica. 2013;98(1):50-56.

64. Kadin ME, Pinkus JL, Pinkus GS, et al. Primary cutaneous ALCL with phosphorylated/activated cytoplasmic ALK and novel phenotype: EMA/MUC1+, cutaneous lymphocyte antigen negative. Am J Surg Pathol. 2008;32(9):1421-1426.

65. Lamant L, Pileri S, Sabattini E, et al Cutaneous presentation of ALK-positive anaplastic large cell lymphoma following insect bites: evidence for an association in five cases. Haematologica. 2010;95(3):449455.

66. Chavan RN, Bridges AG, Knudson RA, et al Somatic rearrangement of the TP63 gene preceding development of mycosis fungoides with aggressive clinical course. Blood Cancer J. 2014; 253.

67. Ohgami RS, Ma L, Merker JD, et al. STAT3 mutations are frequent in CD30+ T-cell lymphomas and T-cell large granular lymphocytic leukemia. Leukemia 2013;27: 2244 2247

68. Crescenzo R, Abate F, Lasorsa E, et al. Convergent mutations and kinase fusions lead to oncogenic STAT3 activation in anaplastic large cell lymphoma. Cancer Cell. 2015;27(4):516-532.

69. Velusamy T, Kiel MI, Sahasrabuddhe AA, et al. A novel recurrent NPM1-TYK2 gene fusion in cutaneous CD30-positive lymphoproliferative disorders. Blood. 2014:124(25): 3768-3771.

70. Hanahan D, Weinberg RA. Hallmarks of cancer: the next generation. Cell. 2011;144 (5):646-674

71. Hassler MR, Pulverer W, Lakshminarasimhan $\mathrm{R}$, et al. Insights into the pathogenesis of anaplastic large-cell lymphoma through genome-wide DNA methylation profiling. Cell Rep. 2016;17(2):596608.

72. Kim KH, Roberts CW. Targeting EZH2 in cancer. Nat Med. 2016;22(2):128-134.

73. Yi S, Sun J, Oiu L, et al. Dual role of EZH2 in cutaneous anaplastic large cell lymphoma: promoting tumor cell survival and regulating tumor microenvironment. J Invest Dermatol. 2018;138(5):1126-1136.

74. Allan RS, Nutt SL. Deciphering the epigenetic code of $T$ lymphocytes. Immunol Rev. 2014;261(1):50-61.

75. Persson JL. miRNA in mycosis fungoides and skin inflammation. APMIS. 2013;121 (11):1017-1019.

76. Ralfkiaer U, Hagedorn PH, Bangsgaard N, et al. Diagnostic microRNA profiling in cutaneous T-cell lymphoma (CTCL). Blood 2011:118(22):5891-5900.

77. Benner MF, Ballabio E, van Kester MS, et al. Primary cutaneous anaplastic large cell lymphoma shows a distinct miRNA expression profile and reveals differences from tumorstage mycosis fungoides. Exp Dermatol. 2012;21(8):632-634

78. Sandoval J, Diaz-Lagares A, Salgado R, et al. MicroRNA expression profiling and DNA methylation signature for deregulated microRNA in cutaneous T-cell lymphoma. Invest Dermatol. 2015;135(4):1128-1137.

79. Lawrie CH. MicroRNA expression in lymphoid malignancies: new hope for diagnosis and therapy? J Cell Mol Med. 2008;12(5a): 1432-1444.

80. Liu C, Iqbal J, Teruya-Feldstein J, et al MicroRNA expression profiling identifies molecular signatures associated with anaplastic large cell lymphoma. Blood. 2013;122(12):2083-2092

81. Hassler MR, Klisaroska A, Kollmann K, et al Antineoplastic activity of the DNA methyltransferase inhibitor 5-aza-2'-deoxycytidine in anaplastic large cell lymphoma. Biochimie. 2012;94(11):2297-2307.

82. Wong HK. Novel biomarkers, dysregulated epigenetics, and therapy in cutaneous T-cell lymphoma. Discov Med. 2013;16(87):71-78.

83. Ellisen LW, Bird J, West DC, et al. TAN-1, the human homolog of the Drosophila notch gene, is broken by chromosomal translocations in T lymphoblastic neoplasms. Cell. 1991;66(4):649-661.

84. Weng AP, Ferrando AA, Lee W, et al Activating mutations of NOTCH1 in human $T$ cell acute lymphoblastic leukemia. Science. 2004:306(5694):269-271.

85. Jundt F, Anagnostopoulos I, Forster R, et al Activated Notch1 signaling promotes tumor cell proliferation and survival in Hodgkin and anaplastic large cell lymphoma. Blood. 2002;99(9):3398-3403.

86. Jundt F, Probsting KS, Anagnostopoulos I, et al. Jagged1-induced Notch signaling drives proliferation of multiple myeloma cells Blood. 2004:103(9):3511-3515.

87. Rosati E, Sabatini R, Rampino G, et al. 
Constitutively activated Notch signaling is involved in survival and apoptosis resistance of B-CLL cells. Blood. 2009;113(4):856-865.

88. Tohda S, Nara N. Expression of Notch1 and Jagged1 proteins in acute myeloid leukemia cells. Leuk Lymphoma. 2001;42(3):467-472.

89. Kamstrup MR, Biskup E, Gniadecki R. Notch signalling in primary cutaneous CD30+ lymphoproliferative disorders: a new therapeutic approach? Br J Dermatol. 2010;163(4):781-788.

90. Sharpless NE, DePinho RA. The INK4A/ARF locus and its two gene products. Curr Opin Genet Dev. 1999;9(1):22-30.

91. Scarisbrick JJ, Woolford AJ, Calonje E, et al. Frequent abnormalities of the p15 and p16 genes in mycosis fungoides and sezary syndrome. J Invest Dermatol. 2002;118(3):493499.

92. Navas IC, Algara P, Mateo M, Martinez P, Garcia C, Rodriguez JL, et al. p16(INK4a) is selectively silenced in the tumoral progression of mycosis fungoides. Lab Invest. 2002;82(2):123-132.

93. Navas IC, Ortiz-Romero PL, Villuendas R, et al. p16(INK4a) gene alterations are frequent in lesions of mycosis fungoides. Am J Pathol. 2000;156(5):1565-1572

94. Gallardo F, Esteller M, Pujol RM, et al. Methylation status of the p15, p16 and MGMT promoter genes in primary cutaneous T-cell lymphomas. Haematologica. 2004;89(11):1401-1403.

95. Laharanne E, Chevret E, Idrissi $Y$, et al. CDKN2A-CDKN2B deletion defines an aggressive subset of cutaneous T-cell lymphoma. Mod Pathol. 2010;23(4):547-558.

96. Nicolae-Cristea AR, Benner MF, Zoutman $\mathrm{WH}$, et al. Diagnostic and prognostic signif- icance of CDKN2A/CDKN2B deletions in patients with transformed mycosis fungoides and primary cutaneous CD30-positive lymphoproliferative disease. $\mathrm{Br} \mathrm{J}$ Dermatol. 2015;172(3):784-788.

97. Szuhai K, van Doorn R, Tensen CP, et al. Array-CGH analysis of cutaneous anaplastic large cell lymphoma. Methods Mol Biol. 2013;973:197-212.

98. Mao X, Orchard G, Lillington DM, et al. Genetic alterations in primary cutaneous CD30+ anaplastic large cell lymphoma. Genes Chromosomes Cancer. 2003;37(2): 176-185.

99. Kempf W, Pfaltz K, Vermeer $\mathrm{MH}$, et al. EORTC, ISCL, and USCLC consensus recommendations for the treatment of primary cutaneous CD30-positive lymphoproliferative disorders: lymphomatoid papulosis and primary cutaneous anaplastic large-cell lymphoma. Blood. 2011;118 (15):4024-4035.

100. Vu K, Ai W. Update on the treatment of anaplastic large cell lymphoma. Curr Hematol Malig Rep. 2018;13(2):135-141.

101. Prince HM, Kim YH, Horwitz SM, et al. Brentuximab vedotin or physician's choice in CD30-positive cutaneous T-cell lymphoma (ALCANZA): an international, openlabel, randomised, phase 3, multicentre trial. Lancet. 2017;390(10094):555-566.

102. Enos TH, Feigenbaum LS, Wickless HW. Brentuximab vedotin in $\mathrm{CD} 30(+)$ primary cutaneous T-cell lymphomas: a review and analysis of existing data. Int J Dermatol. 2017;56(12):1400-1405.

103. Nairismagi M, Gerritsen ME, Li ZM, et al. Oncogenic activation of JAK3-STAT signaling confers clinical sensitivity to PRN371, a novel selective and potent JAK3 inhibitor, in natural killer/T-cell lymphoma. Leukemia. 2018;32(5):1147-1156.

104. Mosse YP, Lim MS, Voss SD, et al. Safety and activity of crizotinib for paediatric patients with refractory solid tumours or anaplastic large-cell lymphoma: a Children's Oncology Group phase 1 consortium study Lancet Oncol. 2013;14(6):472-480.

105. Moretta A, Parolini S, Castriconi R, et al Function and specificity of human natural killer cell receptors. Eur J Immunogenet. 1997;24(6):455-468.

106.Poszepczynska-Guigne E, Schiavon V, D'Incan M, et al. CD158k/KIR3DL2 is a new phenotypic marker of Sezary cells: relevance for the diagnosis and follow-up of Sezary syndrome. J Invest Dermatol. 2004;122(3): 820-823.

107. Ott CJ, Wu CJ. HDAC inhibitors finally open up: chromatin accessibility signatures of CTCL. Cancer Cell. 2017;32(1):1-3.

108. Schcolnik-Cabrera A, Dominguez-Gomez G, Duenas-Gonzalez A. Comparison of DNA demethylating and histone deacetylase inhibitors hydralazine-valproate versus vorinostat-decitabine incutaneous $t$-cell lymphoma in HUT78 cells. Am J Blood Res. 2018;8(2):5-16.

109. Kim SR, Lewis JM, Cyrenne BM, et al. BET inhibition in advanced cutaneous $\mathrm{T}$ cell lymphoma is synergistically potentiated by BCL2 inhibition or HDAC inhibition. Oncotarget. 2018;9(49):29193-29207.

110. Moyal L, Yehezkel S, Gorovitz B, et al. Oncogenic role of microRNA-155 in mycosis fungoides: an in vitro and xenograft mouse model study. Br J Dermatol. 2017; 177(3):791-800 